Gut, 1968, 9, 42-45

\title{
Treatment of gastric ulcer with carbenoxolone: antagonistic effect of spironolactone
}

\author{
RICHARD DOLL, M. J. S. LANGMAN, AND H. H. SHAWDON \\ From the Medical Research Council's Statistical and Gastroenterological Research Units, and the \\ Department of Radiology, Central Middlesex Hospital, London
}

Controlled trials have shown that the rate of healing of gastric ulcers is increased by treatment with carbenoxolone sodium, but that fluid retention is produced as a side effect sufficiently often to limit the freedom with which the drug can be prescribed (Doll, Hill, Hutton, and Underwood, 1962; Doll, Hill, and Hutton, 1965; Horwich and Galloway, 1965). We have, therefore, sought a method of using carbenoxolone which would minimize the side effects without reducing its therapeutic value and have examined the effect of two dose levels of the drug and two different diuretic regimes.

\section{METHOD}

The trial was carried out in the same way as previous trials of out-patient treatment for gastric ulcer (Doll et al., 1962, 1965). Patients in whom a diagnosis of gastric ulcer had been made and who were thought suitable for out-patient treatment were referred to a special clinic. On their first attendance they were referred for a further barium meal examination and were seen again three days later.

Patients were accepted for the trial only if a gastric ulcer niche was clearly visible, measurable, and of more than $10 \mathrm{sq} \mathrm{mm}$ area in maximum profile, and there was no overriding clinical or social reason for their exclusion. They were excluded if there was radiological or clinical suspicion of malignancy, if there was associated duodenal ulceration or deformity, or if there was more than one gastric ulcer crater. Patients aged 70 years or more were excluded because previous trials had shown that the risk of fluid retention during carbenoxolone treatment was particularly common in the elderly, and patients with evidence of heart disease or hypertension were excluded because the use of high doses of carbenoxolone in these patients was contraindicated.

The remaining patients were treated with carbenoxolone sodium in a dose of 50 or $\mathbf{1 0 0} \mathrm{mg}$ three times a day for four weeks, except that those in the high dose group who were 65 years of age or more were given only $75 \mathrm{mg}$ three times a day. Treatment was combined either with spironolactone (aldactone A), $25 \mathrm{mg}$ four times a day routinely from the start of treatment, or with hydrochlorthiazide in a dose of $50 \mathrm{mg}$ daily when indicated clinically: that is, when oedema developed, the blood pressure rose rapidly, or there was an unanticipate $\mathrm{f}$ weight gain, usually of more than $4 \mathrm{lb}$ in a week. A potassium supplement, in the form of effervescent potassium tablets 0.5 to $1.0 \mathrm{~g}$ twice daily, was given to all who were receiving thiazides. The two dose levels of carbenoxolone and the two diuretic regimes were prescribed in random order according to a prearranged schedule, but the randomization was restricted to ensure that each combination of carbenoxolone dosage and diuretic regime was given an equal number of times to patients of each sex.

In addition to these treatments, men were also given stilboestrol $0.5 \mathrm{mg}$ twice daily or dummy tablets of identical appearance. It is shown elsewhere that the effect of this oestrogen treatment was unimportant (Doll, Langman, and Shawdon, 1968) and it has, therefore, been ignored in the analysis of the present results.

All patients were advised to contimue at work if possible, to take a normal diet apart from avoiding fried food, to take a snack between meals, and to stop smoking. They were also given antacid tablets to take when needed for the relief of pain.

Barium meal examination was repeated after five weeks and the results were assessed by the change in size of the ulcer niche.

\section{MATERIAL}

Of the 138 patients referred for treatment, 82 were excluded from the trial for the reasons given in Table I.

\section{TABLE I}

NUMBER OF PATIENTS EXCLUDED FROM TRIAL AND REASONS FOR EXCLUSION

\begin{tabular}{ll} 
Reason for Exclusion & $\begin{array}{l}\text { No. of } \\
\text { Patients }\end{array}$ \\
\hline Ulcer too small or healed & 29 \\
Heart disease or hypertension & 14 \\
Age 70 years or more & 9 \\
Associated duodenal ulser or deformity & 9 \\
Original diagnosis uncertain & 7 \\
Ulcer crater size not measurable & 6 \\
Other reasons (suspected gastric cancer 2; patients & 8 \\
unable to attend regularly 2; surgery indicated, & \\
patient too young, prescribing error, and patient & \\
failed to attend clinic, one each) & \\
Total & 82 \\
\end{tabular}


It was originally intended to study 32 male and 12 female patients, but the proportion of women referred for treatment was unexpectedly high. By the time 12 women had been treated the trial in male patients was still incomplete, but evidence had already been obtained that the lower dose of carbenoxolone was likely to be less effective. Women suitable for inclusion in the trial who were referred for treatment subsequently were, therefore, all given the higher dose. Altogether the effect of different doses of carbenoxolone was studied in 44 patients ( 32 men and 12 women), and the effect of different diuretic regimes in 56 patients (32 men and 24 women).

\section{RESULTS}

The results of treatment, assessed by changes in the size of the ulcer niche on $x$-ray examination, are shown in Table II. In patients given the high doses

\section{TABLE II}

RESULTS OF TREATMENT: CHANGE IN SIZE OF ULCER NICHE IN FIVE WEEKS

$\begin{array}{llll}\text { Treatment Group } & \begin{array}{l}\text { No. of } \\ \text { Patients }\end{array} & \begin{array}{l}\text { No. in whom } \\ \text { Ulcer Healed }\end{array} & \begin{array}{l}\text { Average Change } \\ \text { in Size of } \\ \text { Ulcer Niche (\%) }\end{array}\end{array}$

Carbenoxolone and

thiazides

High dose

High dose

Low dose

Carbenoxolone and

spironolactone

High dose ${ }^{1}$

High dose d $^{2}$

Low dose ${ }^{1}$

Carbenoxolone

High dose

Low dose

Diuretic

Thiazide

Spironolactone

11
6
11

6

6
3
4

-90.8
-88.6

$-88 \cdot 6$
$-50 \cdot 4$

11

11
6
11

$$
3
$$

3
$\mathbf{0}$
1

$-73 \cdot 3$

$\begin{array}{r}73 \cdot 2 \\ \hline\end{array}$

11

1

$-28 \cdot 1$

22
22

9
5

$-82 \cdot 0$

$-39 \cdot 3$

$-74 \cdot 5$

$-39 \cdot 1$

'Patients allocated high or low doses and one or other diuretic regime at random.

${ }^{3}$ Consecutive female patients given high doses and allocated one or other diuretic regime at random (see text).

of carbenoxolone, more of the ulcers healed completely (nine out of 22 or $42 \%$ ) than in patients given the low doses (five out of 22 or $23 \%$ ), and the reduction in size of the ulcer niche was also, on average, appreciably greater $(82 \%$ of the initial size against $39 \%$ ). Similar differences were also found between the groups of patients given thiazides when necessary to control water retention or spironolactone routinely from the start of treatment. In 13 out of 28 patients on the thiazide regime ( $46 \%)$ the ulcers healed completely against four out of 28 patients on the spironolactone regime $(14 \%)$, and the average reduction in the size of the ulcer was respectively $75 \%$ and $39 \%$. Since both the dose of carbenoxolone and the diuretic regime appeared to be important, the statistical significance of the differences in the amount of healing was assessed separately for each pair of contrasting treatments (high dose and thiazide against low dose and thiazide, high dose and spironolactone against low dose and spironolactone, etc.), and the results were combined for the two comparisons between dose levels and the two comparisons between diuretic regimes. In each case Wilcoxon's ranking test (see Doll et al., 1965) showed that the probability of obtaining differences as great or greater than those observed by chance was $1 \%$ or less.

The comparability of the patients in the four treatment groups is shown in Table III in respect of their age and sex, their smoking habits and response to the advice to stop smoking, and the initial size of their ulcers. The only important differences between

\section{TABLE III}

COMPARABILITY OF PATIENTS IN DIFFERENT TREATMENT GROUPS

\begin{tabular}{|c|c|c|c|c|}
\hline \multirow[t]{3}{*}{ Characteristic } & \multicolumn{4}{|c|}{ No. of Patients } \\
\hline & \multicolumn{2}{|c|}{ Carbenoxolone } & \multicolumn{2}{|l|}{ Diuretic } \\
\hline & $\begin{array}{l}\text { High } \\
\text { Dose }\end{array}$ & $\begin{array}{l}\text { Low } \\
\text { Dose }\end{array}$ & Thiazide & $\begin{array}{l}\text { Spirono- } \\
\text { lactone }\end{array}$ \\
\hline Sex of patient $\mathbf{M}$ & $\begin{array}{r}16 \\
6\end{array}$ & $\begin{array}{r}16 \\
6\end{array}$ & $\begin{array}{l}16 \\
12\end{array}$ & $\begin{array}{l}16 \\
12\end{array}$ \\
\hline \multicolumn{5}{|l|}{ Age of patient } \\
\hline $\begin{array}{c}\text { Less than } 45 \text { years } \\
45-54 \text { years }\end{array}$ & $\begin{array}{l}4 \\
3\end{array}$ & $\begin{array}{r}3 \\
14\end{array}$ & $\begin{array}{l}8 \\
7\end{array}$ & $\begin{array}{r}2 \\
16\end{array}$ \\
\hline $55-64$ years & 13 & 3 & 10 & 9 \\
\hline $\begin{array}{l}65 \text { years or more } \\
\text { Size of ulcer }\end{array}$ & $2^{1}$ & 2 & 3 & 1 \\
\hline $10-49$ sq mm & 10 & 10 & 16 & 10 \\
\hline 50-99 sq mm & 7 & 5 & 6 & 8 \\
\hline $100 \mathrm{sq} \mathrm{mm}$ or more & 5 & 7 & 6 & 10 \\
\hline \multicolumn{5}{|l|}{$\begin{array}{l}\text { Response to advice } \\
\text { about smoking }\end{array}$} \\
\hline Non-smoker, continued & 7 & 7 & 11 & 9 \\
\hline $\begin{array}{l}\text { Smoker, stopped } \\
\text { Sroker, reduced by t or }\end{array}$ & 3 & 4 & 5 & 3 \\
\hline \multirow{2}{*}{$\begin{array}{l}\text { Sroker, reduced by } \frac{1}{2} \text { or } \\
\text { more } \\
\text { Smoker, other }\end{array}$} & 6 & 1 & 4 & 4 \\
\hline & 6 & 10 & 8 & 12 \\
\hline
\end{tabular}

'One allocated the thiazide regime and the others pironolactone

the groups are that more of the patients in the thiazide group were aged under 45 years and more had ulcers less than $50 \mathrm{sq} \mathrm{mm}$ in area. Patients in these categories, however, respond to out-patient treatment less rapidly, on average, than other patients (Doll and Langman, unpublished data) and this difference cannot have been responsible for the fact that better results were obtained with thiazides than with spironolactone. The apparent paradox that small ulcers respond relatively poorly is due to the fact that while a high proportion heal completely others enlarge and the proportional amount of healing in a given time is, on average, less than with large ulcers.

Details of weight gain and of side effects re- 
TABLE IV

\begin{tabular}{|c|c|c|c|c|c|c|}
\hline \multirow[t]{2}{*}{ Treatment Group } & \multirow{2}{*}{$\begin{array}{l}\text { No. of } \\
\text { Patients }\end{array}$} & \multirow{2}{*}{$\begin{array}{l}\text { Weight: } \\
\text { Mean Change } \\
\text { in lb }\end{array}$} & \multirow{2}{*}{$\begin{array}{l}\text { Blood pressure: No. of } \\
\text { Patients with Rises Greater } \\
\text { than } 50 \mathrm{~mm} \text { Systolic or } 25 \mathrm{~mm} \\
\text { Diastolic during Treatment }\end{array}$} & \multirow{2}{*}{$\begin{array}{l}\text { No. } \\
\text { Requiring } \\
\text { Diuretics }\end{array}$} & \multicolumn{2}{|c|}{ Indication } \\
\hline & & & & & $\begin{array}{l}\text { Weight } \\
\text { Gain }\end{array}$ & $\begin{array}{l}\text { Rising Blood } \\
\text { Pressure }\end{array}$ \\
\hline Carbenoxolone: high dose & & & & & & \\
\hline (a) + thiazide if needed & 17 & $+4 \cdot 5$ & 1 & 10 & $10^{1}$ & $1^{1}$ \\
\hline (b) + spironolactone throughout & 17 & $+2 \cdot 0$ & 1 & 1 & 1 & Nil \\
\hline $\begin{array}{l}\text { Carbenoxolone: low dose } \\
\text { (a) + thiazide if needed } \\
\text { (b) - spironolactone throughout }\end{array}$ & $\begin{array}{l}11 \\
11\end{array}$ & $\begin{array}{r}+4.0 \\
+1.0\end{array}$ & $\begin{array}{l}1 \\
\mathrm{Nil}\end{array}$ & $\begin{array}{l}5 \\
\text { Nil }\end{array}$ & $\begin{array}{l}4 \\
\text { Nil }\end{array}$ & $\begin{array}{l}1 \\
\text { Nil }\end{array}$ \\
\hline
\end{tabular}

The changes in weight are the means of the maximum changes recorded in each patient.

'Dual indication in one patient.

quiring treatment are given in Table IV. Only one of the 28 patients given spironolactone showed any evidence of fluid retention. This patient was given the high dose of carbenoxolone and developed ankle oedema after three weeks' treatment. By contrast, 15 of the 28 patients not given spironolactone showed sufficient evidence of fluid retention to require a diuretic (10 out of 17 in the high dose carbenoxolone group and five out of 11 in the low dose group). All but three in the high dose group responded satisfactorily to treatment with thiazides: the dose of carbenoxolone had to be reduced to 150 and $100 \mathrm{mg}$ daily respectively in two of these whilst the third required injections of frusemide before the ankle oedema was relieved.

Blood pressure levels tended to rise during treatment, and the change was sometimes substantial. Rises in excess of $50 \mathrm{~mm}$ systolic were recorded in single patients with each combination of drugs except for the combination of low dose of carbenoxolone with spironolactone. Two were given thiazide diuretics (one partly because of associated weight gain). The third patient, receiving treatment with the high dose of carbenoxolone and spironolactone, was not given additional diuretics because the blood pressure only rose in the last week of treatment. The mean maximum increase of systolic pressure over the pretreatment reading was $16 \mathrm{~mm}$ $\mathrm{Hg}$ in the thiazide regime group given the high dose of carbenoxolone and $18 \mathrm{~mm} \mathrm{Hg}$ in the low carbenoxolone dose group; by contrast the increase averaged $13 \mathrm{~mm} \mathrm{Hg}$ in the spironolactone-treated group given the high dose of carbenoxolone and 7 $\mathrm{mm} \mathrm{Hg}$ in those given the low dose of carbenoxolone. Details of the comparisons recorded in individual patients are given in Figure 1. Changes in diastolic pressure tended to be similar to, though less marked, than those in systolic pressure. The distribution of pressure changes in the low dose carbenoxolone and spironolactone group, it will be noted, was closely similar to that recorded previously for

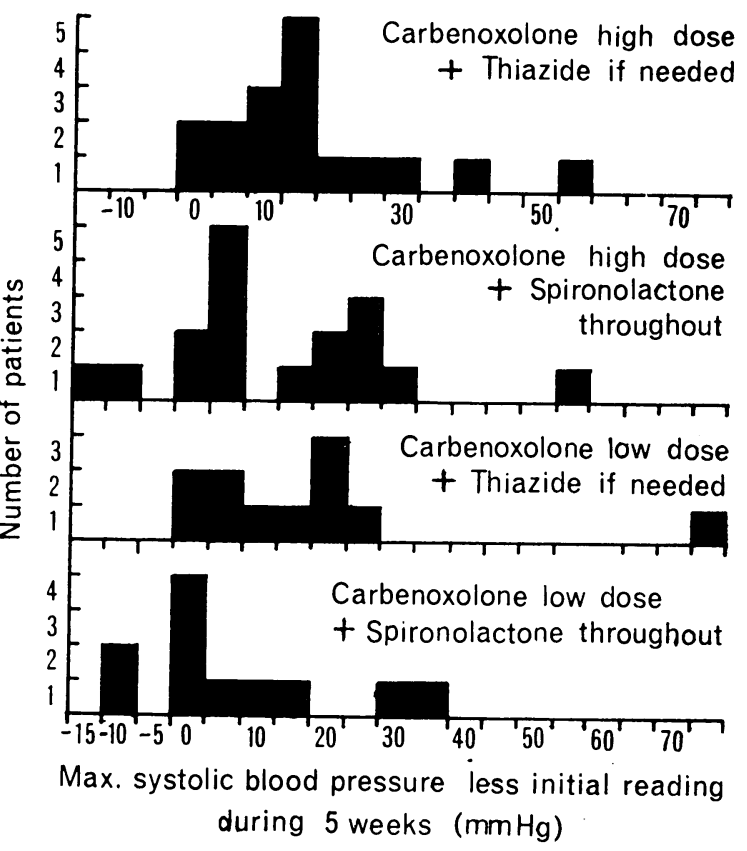

FIG. 1. Comparisons recorded in individual patients.

patients given dummy tablets (mean maximum rise in systolic pressure $8 \mathrm{~mm}$; Doll et al., 1965).

Serum potassium concentrations were measured before and at the end of treatment in 17 patients. There was no consistent change in the concentrations in the seven patients who received spironolactone as well as carbenoxolone, nor in the three patients in the thiazide regime group treated with the high dose of carbenoxolone who did not require a diuretic. The remaining seven patients all received treatment with thiazide diuretics and the serum potassium concentration fell in all but one. The 
average degree of change was similar in the three patients given the high dose of carbenoxolone and the four given the low dose, the mean fall being 1.5 milli-equivalents per litre.

\section{DISCUSSION}

The healing effect observed in this trial with the higher dose of carbenoxolone and no spironolactone was slightly better than that recorded previously (Doll et al., 1962, 1965). The mean reduction in ulcer size after treatment was $91 \%$ compared with $78 \%$ and $79 \%$ in each of the two previous trials. Side effects from fluid retention were, however, frequent. The amount of healing and the incidence of side effects were both diminished if the dose of carbenoxolone was reduced or if spironolactone was given, and a combination of $150 \mathrm{mg}$ of carbenoxolone daily with spironolactone gave results which were similar to those that had previously been obtained with dummy tablets.

Turpie and Thompson (1965) found that side effects of fluid retention persisted when the dose of carbenoxolone was lowered to $150 \mathrm{mg}$ daily, but Montgomery (1967) in a larger investigation noted that side effects only occurred in individuals who were over 60 years of age and hypertensive. Our results support the findings of Turpie and Thompson, though it should perhaps be noted that we were prepared to prescribe diuretics for unexplained weight gain before oedema developed clinically. The considerable superiority in healing effect of the higher dose of carbenoxolone would seem at least to counterbalance the high frequency of side effects, particularly since these were almost always completely reversed by the administration of a thiazide diuretic.

The mechanism by which spironolactone blocks ulcer healing is obscure. Shields and his colleagues have shown that this substance will interfere with potassium transport mechanisms in the gut as well as the kidney (Elmslie, Mulholland, and Shields, 1966), and it may be that the mechanism by which carbenoxolone promotes ulcer healing depends upon the integrity of systems involved in electrolyte transport. Fluid retention would not seem to be a necessary feature for ulcer healing to occur, since

'The average amount of healing in all the 30 patients in the first trial was $72 \%$; in 15 patients who received carbenoxolone sodium the ulcers healed on average by $79 \%$; and in the 15 patients who received carbenoxolone acid by $66 \%$. In all subsequent trials, carbenoxolone sodium alone has been used. in our patients there was no correlation between the rate of healing and the avidity with which fluid was retained; furthermore the rate of ulcer healing was not reduced in those patients given thiazide diuretics. These findings make it very unlikely that radiological healing seen after carbenoxolone treatment is due to oedematous filling of the ulcer crater, a conclusion which is supported by other evidence. Gastric ulcer patients treated with carbenoxolone as a holding measure while awaiting surgery have proved to have healed ulcers at the time of operation, and a high proportion of those ulcers which appeared radiologically to have healed after one month's treatment with carbenoxolone remained healed at review one year later (Doll and Langman, unpublished data).

\section{SUMMARY}

In an attempt to find a combination of treatments which would minimize side effects but retain ulcer healing properties, carbenoxolone sodium was administered to out-patients with chronic gastric ulcers in a dose of 50 or $100 \mathrm{mg}$ three times a day, treatment being combined either with spironolactone $25 \mathrm{mg}$ four times a day given throughout the four weeks' treatment, or with a thiazide diuretic which was administered if indicated clinically.

The lower dose of carbenoxolone gave a lower incidence of side effects, but this benefit was outweighed by a markedly reduced rate of ulcer healing. In addition spironolactone seemed to block both the side effects and healing properties of carbenoxolone; in contrast, treatment with a thiazide diuretic did not interfere with ulcer healing.

\section{REFERENCES}

Doll, R., Hill, I. D., Hutton, C., (1965). Treatment of gastric ulcer with carbenoxolone sodium and oestrogens. Gut, 6.

,,-- , and Underwood, D., II (1962). Clinical trial of a triterpenoid liquorice compound in gastric and duodenal ulcer. Lancet, 2, 793-796.

—, Langman, M. J. S., and Shawdon, H. H. (1968). Treatment of gastric ulcer with oestrogens. Gut, 9, 46-47.

Elmslie, R. G., Mulholland, A. T., and Shields, R. (1966). Blocking by spironolactone (SC 9420) of the action of aldosterone upon the intestinal transport of potassium, sodium and water. Gut, 7, 697-699.

Horwich, L., and Galloway, R. (1965). Treatment of gastric ulceration with carbenoxolone sodium: clinical and radiological evaluation. Brit. med. J., 2, 1274-1277.

Montgomery, R. D. (1967). Side-effects of carbenoxolone sodium: a study of ambulant therapy of gastric ulcer. Gut, 8, 148-150.

Turpie, A. G. G., and Thompson, T. J. (1965). Carbenoxolone sodium in the treatment of gastric ulcer with special reference to side-effects. Gut, 6, 591-594. 